\title{
RAZÔES DE DESMAME E DE INTRODUÇÂO DA MAMADEIRA: UMA ABORDAGEM ALTERNATIVA PARA SEU ESTUDO*
}

\author{
Marina Ferreira Rea** \\ Rosa Cukier***
}

\begin{abstract}
REA, M.F. \& CUKIER, R. Razóes de desmame e de introduçăo da mamadeira: uma abordagem alternativa para seu estudo. Rev. Saúde públ., S. Paulo, 22: $184-91$, 1988.
\end{abstract}

RESUMO: Descrevem-se as razōes alegadas pelas mães para o desmame e a introduçăo de mamadeira em uma amostra de 875 mulheres, de um bairro de Săo Paulo, que deram a luz em uma maternidade pública local, em 1985. Estas mães fizeram parte de um estudo de intervençåo próamamentação desenvolvido nos serviços públicos de saúde por elas freqüentados até o $4^{\circ}$ més de vida das crianças. Discutem-se formas diferentes de coleta de dados sobre o processo de desmame e apresentam-se três maneiras distintas de analisar tais dados. Conclui-se que as razóes mais alegadas pelas mães para introduzir a mamadeira, quando oolhidas em várias entrevistas com elas ("entrevistas múltiplas") săo: trabalho fora do lar $(20,5 \%)$, nervosismo $(12,5 \%)$ e conveniência da mãe $(11,0 \%)$. Entretanto, quando tais razőes são argüidas em apenas um primeiro contacto, assim aparecem: choro do bebê $(23,0 \%)$, conceitos ou suposiçס̄es sobre o aleitamento $(12,5 \%)$ e trabalho fora do lar $(11,0 \%)$. Estas diferenças no perfil de razőes conforme o tipo de coleta, não aparecem evidentes no caso de razठes para o desmame completo, entretarto, acreditando-se ser o desmame um processo, onde razões de introdução da mamadeira e do desmame devem ser vistas como um todo, as autoras apontam para a vantagem de se utilizar todas as respostas da măe em diversos momentos ("entrevistas múltiplas") no sentido de melhor contribuir para a elucidação daquele processo. $O$ agrupamento das razð̋es conforme responsabilização pelo desmame mostra que, ao se permití que a mãe reveja seu discurso em várias entrevistas, ao invés de em uma única, ela passa a responsabilizar mais a si própria (ato de vontade) do que o bebê ou o seu próprio corpo. Apontam-se limites do sistema de saúde em interferir no processo de desmame precoce e perspectivas de intervençăo de ordem mais ampla.

UNITERMOS: Desmame. Alimentação artificial. Mães. Fatores sర6cio-econômicos.

\section{INTRODUÇÃO}

Diversos estudos têm sido publicados a respeito de amamentaçăo onde săo avaliadas as razóes que alegam as mães para desmamar ou para introduzir a mamadeira mantendo a prática do aleitamento misto. Esses trabalhos, entretanto, de maneira geral não foram desenhados com o fim principal de estudar tais razōes, mas sim são resultados da análise de algumas variáveis aduzidas àquelas que cobrem o objetivo fundamental para o qual o estudo foi delineado.

Dessa forma, as razões mais freqüentes para introdução de suplementos (sejam substitutos do leite materno, sejam sólidos) têm sido a insuficiência de leite e o trabalho da mãe $e^{1 / 10}$. Para a in- terrupção completa do aleitamento natural, os estudos em geral listam como mais alegadas: insuficiência de leite, nova gravidez, doença da mãe ou do bebê, ou rejeiçăo da criança em mamar por estar muito grande ${ }^{1,8,9}$. Tais razð̋es são diferentes quando os trabalhos săo conduzidos em áreas rurais ou urbanas, ou mesmo diferem conforme idade em que o desmame ocorre.

A repetiçăo da alegaçăo "o leite secou", ou leite insuficiente, levou Gussler e Briesemeister ${ }^{6}$ a levantarem a hipótese de uma "síndrome do leite insuficiente" como um fato transcultural, qual seja, que perpassaria às diferentes culturas do mundo. Este tema foi retomado e re-analisado por Greiner e col. ${ }^{5}$, que refutaram a tese de que a insuficiência de leite seria um fato inexorável,

Parte do projeto "Superaçăo das dificuldades de amamentaçăo nos grupos sócio-econômicos de baixa renda". CEBRAP/Fundação Ford. Doaçăo 840/0630.

* Divisão de Saúde Materno-Infantil do Instituto de Saúde - Caixa Postal 8027-0 - 01000 - São Paulo, SP - Brasil. Centro Brasileiro de Análise e Planejamento (CEBRAP) - Rua Morgado Mateus, 615 - 04015 - São Paulo, SP Brasil

*** Centro Brasileiro de Análise e Planejamento (CEBRAP) - Rua Morgado Mateus, 615 - 04015 - Såo Paulo, SP. 
sem porém esgotar a questão.

No nosso meio as razóes alegadas para a introduçăo da mamadeira ou para o desmame não fogem das acima apontadas ${ }^{13}$.

Vários autores têm chamado a atenção para as dificuldades metodologicas envolvidas no estudo das causas do desmame $e^{2,15}$. Tais dificuldades incluem desde a coleta de dados (momento em que ocorre, treinamento do entrevistador, questionário utilizado) até a fase de análise (metodologia ou testes estatísticos apropriados).

E muito difícil obter-se das mães respostas completas, confiáveis, quando uma entrevista é parte de um estudo transversal. Sabe-se que as mães tendem a dar respostas socialmente mais convincentes e que não firam sua auto-estima?. Apenas quando as causas săo inequívocas (tipo "o bebê morreu", "a mãe foi hospitalizada por doença grave"), e que são infreqüentes nos estudos em geral, é que năo haveria restriçốes ao estudo transversal.

O estudo de seguimento, com entrevistas periódicas em torno do desmame, parece mais apropriado, embora a possibilidade de intervenção do entrevistador acabe sendo grande. Apesar de que nảo tem sido reportada, esta intervenção deve fatalmente ocorrer à medida em que as mães, inseguras e ansiosas por apoio, acabam por estabelecer relacionamento agradável com alguém que se detém em discutir com elas as questőes da alimentaçăo e cuidado infantil. Isto lhes diminui a angústia, podendo até levá-las ao aumento da produção do leite e maior duraçăo do aleitamento.

A utilização do estudo de seguimento com mães da periferia de Săo Pauloti levou a pensar que só através de recuperaçóes de respostas a perguntas mal respondidas nos primeiros contactos, quando entảo já se estabeleceu o devido "rapport", é que permite chegar mais perto daquilo que, de fato, levou a măe a desmamar. $O$ trabalho de Sjölin e col. ${ }^{15}$ um dos mais bem conduzidos nesse sentido, apresenta resultados importantes em que as razóes que levam ao desmame são complexas e resultam de somatória de "pequenas" razóes; além disso, mostra que as mães tendem a colocar suas próprias razőes em outras mães, como se não admitissem para si o que podem admitir (sem culpa ou angústia) para suas vizinhas ou parentes.

Uma outra tentativa metodologica é a entrevista em profundidade, utilizando-se gravador e tendo uma conversa livre e prolongada sobre temas pertinentes com a mãe. Este procedimento é dispendioso porque necessita um entrevistador qualificado. Em nosso meio, um único estudo ${ }^{11}$ conhecido utilizando tais entrevistas, foi feito com 30 mães em São Paulo, que referiram como uma das razőes principais para o desmame precoce, a ignorância sobre como lidar com os problemas comuns da amamentaçăo (seio engurgitado, mamilo ferido e outros).

Metodologia não encontrada com freqũência, mas que certos pesquisadores já têm referido como mais promissora para o assunto em questão, é a discussăo em grupo. Projetos levados a efeito na Tanzânia e Sri Lanka ${ }^{12}$ experimentaram tal metodologia na discussão das razōes de desmame com grupos de mães. Foi possível ver, por exemplo, como um fato circunstancial - que no grupo é narrado por uma outra mãe - pode levar a măe a reconstituir o motivo que a levou ao abandono do aleitamento e início da mamadeira.

No nosso meio, Cukier ${ }^{3}$ criou um instrumento de coleta de dados calcado nos conceitos de projeçăo e atitude, visando afastar o estímulopergunta da mãe. Consistia de curtas estórias sobre situaçరes de aleitamento através das quais se investigava as atitudes maternas. Apesar das dificuldades encontradas para a validação deste instrumento, os resultados apontaram na direçăo de razőes de introduçăo de mamadeira e desmame mais complexas. Por exemplo: ansiedade e culpa materna pelo choro e desconforto do bebê foi uma das categorias de respostas mais mencionadas.

O que não podemos perder de vista é que o desmame (mais comparável à "weaning" para o idioma inglês e não a "sevrage", do francês), é um processo social, e como tal năo deve ser visto como fato isolado, unicausal, pontual; exceto em raríssimas exceçóes. Parece-nos legítimo compará-lo ao processo de adoecimento e chegada à morte, que deve ser descrito em um atestado de óbito - neste, estarão contidas as causas básicas, associadas e final do 6bito. Comparativamente, no processo de desmame, o que em geral se consegue apurar nos estudos, alegado por măes ou pessoal de saúde, é a "causa final" (ex.: o leite secou). Sjölin ${ }^{16}$ já chamava a atenção para a importância das "causas associadas" (que ele chamou geradoras de "crises na lactaçăo", e que podem levar à interrupção por horas ou dias de amamentaçăo). Devemos nos esforçar por buscar as causas básicas desencadeadoras do processo, conquanto há que registrar as associadas, pois sem elas muitas vezes o fato terminal (interrupção de dar leite do peito) năo ocorre e o processo de desmame não se elucida por inteiro.

No estudo que apresentamos a seguir, procuramos contornar toda essa problemática, reunindo dados quantitativos e qualitativos, através de uma combinaçăo metodológica tanto de coleta de dados como de análise. $O$ objetivo do presente trabalho é descrever e analisar as razoes de desmame e de introduçăo da mamadeira em popu- 
laçơes de mães pertencentes a familias de baixa renda em Săo Paulo, que fizeram parte de um projeto de intervençăo pró-amamentaçăo conduzido pelos serviços de saúde.

\section{METODOLOGIA}

Durante um ano (1985) várias açōes próamamentaçåo foram desenvolvidas em uma maternidade federal e centros de saúde estaduais e municipais do Distrito Sanitário da Penha (São Paulo).

Participaram das ações 875 mães pertencentes a familias de baixa renda, $18 \%$ das quais eram "mães solteiras" e apenas $6 \%$ analfabetas*.

Durante a intervençăo, todas as mães que deram a luz na maternidade escolhida, residentes no bairro, foram convidadas a comparecer mensalmente até o quarto mês de vida da criança aos Centros de Saúde, onde foram conduzidos três grupos de açōes pró-aleitamento: grupos de måxes, atendimento individual e audio-visual.

Nem todas as mães compareceram todos os meses aos Centros de Saúde. As ausências deramse por uma morte materna, 6 mortes de bebês, 9 doaçōes e, as demais, por mudanças de endereço. Das 736 mães recuperadas no final do estudo 365 compareceram aos Centros de Saúde e 371 tiveram suas respostas sobre razões de desmame, colhidas em entrevistas a domicnlio no final do quarto mês.

O material utilizado e descrito a seguir foi coletado e analisado de três formas distintas: primeiramente, no que se pode chamar de "entrevista única", em que a coleta das razóes de introdução da mamadeira e desmame foi feita através de perguntas diretas à mãe, no momento em que o fato ocorreu, a fim de evitar possíveis recons-truçóes compensatórias ou distorcidas em suas respostas.

Houve a preocupaçăo de treinar cuidadosamente as entrevistadoras, bem como permitir até quatro razóes por mãe, a fim da dar conta da multicausalidade e da complexidade que normalmente envolve a questão do desmame.

Em segundo lugar, por "entrevistas múltiplas", aproveitou-se o fato de termos vários contatos com as mães que compareciam aos Centros de Saúde, bem como o relato escrito de todos os seus comentários, para, ao invés de eliminar as reconstruçōes ou inconsistências do discurso, considerá-las. Assim foram cotejadas entre si todas as tazð̌es alegadas no total de visitas das mães aos Centros de Saúde. Pensou-se que esta forma de coleta poderia ser mais adequada para captar as verdadeiras razōes maternas, uma vez que nåo procurava artificialmente, dar uma resposta "simples, coerente e consistente".

Convém ressaltar que raramente o discurso humano é linear, sobretudo quando o fato ao qual este discurso se refere é dinâmico, sujeito a mudanças a cada dia ou mesmo em diferentes momentos da vida. Tanto na primeira como na segunda forma de coleta é o número de respostas que constitui o denominador dos dados apresentadas.

Foi apresentada também uma nova maneira de categorizar os dados obtidos nas duas diferentes formas de coleta (única e múltipla), onde se agrupam as razőes obtidas por área de "responsabilidade" prioritária na ação do desmame. Quatro áreas foram destacadas:

\section{Deficiências orgânicas da mãe}

A ênfase dada aqui é sobre as deficiências do corpo da mảe que a impediram de amamentar: leite insuficiente, leite fraco, doenças da mãe e problemas com a mama estão aqui incluídos. Neste tipo de razão, a mulher tem uma postura passiva diante do desmame, ou introdução da mamadeira, pois tudo se passa como se ela quisesse continuar amamentando, mas razões de força "maior" - o funcionamento do corpo ou a saúde - a impedem.

\section{Atribuiçăo de "responsabilidade" ao bebê}

Aqui também a postura da mulher é passiva diante do desmame, pois em última análise, seja porque o bebê chora muito, ou porque ele não dorme, ou ainda porque ele não quer, em última instância é o bebê o "responsável" pela introdução da mamadeira ou o desmame completo.

\section{Atribuição de "responsabilidade" à mãe}

Este grupo de razões supōe a mãe como ativa no processo de desmame. É ela quem decide se intraduz ou não a mamadeira. Aqui se incluem as seguintes categorias de razőes: mãe não quer amamentar; anticoncepção; mãe considera o aleitamento exclusivo insuficiente para o bebê, seja porque mamadeira é um alimento melhor ou porque um bebê precisa de outros alimentos; mãe fica nervosa com o aleitamento exclusivo; e trabalho da mãe.

\section{Influência de terceiros}

Aqui sảo os profissionais de saúde e/ou parentes, vizinhos ou amigos, os "responsáveis" 
pela introdução da mamadeira e desmame. A eles é atribuído o poder de influenciar a decisão materna de aleitar ou não seu bebê.

A seguir é apresentado um exemplo para ilustrar como validamos as respostas e as categorizamos: Uma măe $X$, em sua segunda visita ao Centro de Saúde, alegou que havia introduzido a mamadeira porque seu leite era insuficiente e porque logo teria que voltar a trabalhar.

Na terceira visita (um mês após à segunda) ao Centro de Saúde essa mesma mãe, quando perguntada sobre porque havia introduzido a mamadeira no mês anterior, dizia que havia estado muito nervosa com o marido alcoblatra e que o choro do bebê a irritava muito. A mamadeira havia sido uma tentativa de aquietar o bebê e ficar, ela mesma, mais tranquila.

$\mathrm{Na}$ entrevista única as razőes de introduçăo da mamadeira computadas são aquelas duas da segunda visita, ou seja: leite insuficiente e trabalho da mulher. Ambas as categorias de respostas foram registradas.

Já nas entrevistas múltiplas além destas duas categorias inicialmente mencionadas, foram registradas também as categorias "nervoso da måe", "influência de terceiros (do marido)" e "choro do bebê". Nesta forma de análise todo o discurso da mãe ao longo dos quatro meses de cobertura do atendimento é considerado.

Ao agrupar os dados de acordo com áreas de "responsabilidade" prioritárias, a codificaçăo assim se processa:

Leite insuficiente: deficiências orgânicas. Isto porque tudo se passa como se a mãe de fato quisesse amamentar, porém, uma deficiência de seu organismo (que não produz leite suficiente) a impede.
Trabalho da mulher: atribuição de "responsabilidade" à mãe. É a mulher quem decide, ou quem quer, ou ainda quem precisa ir trabalhar. Ela é o sujeito da ação.

Nervoso da mulher: atribuição de "responsabilidade" à mãe. É a mulher quem decide introduzir a mamadeira para que, acalmando o bebê, aquiete seus nervos.

Choro do bebê: atribuição de "responsabilidade" ao bebê. É algo que o bebê faz, em última instância, que motiva a mãe para introduzir a mamadeira.

Alcoolismo do marido: atribuição de "responsabilidade" a terceiros. Aqui a leitura possível seria: a mãe gostaria de amamentar porém seu marido a impediu.

A análise por atribuiçăo de "responsabilidades" procura dar conta de todas as leituras possiveis do "discurso da măe", para, no final, quotejar as freqüências por áreas de "responsabilidade".

\section{RESULTADOS}

No estudo iniciado com 875 mães, foram recuperadas ao final de quatro meses de seguimento e responderam à "entrevista única" 736: $404 \mathrm{mu}$ lheres que desmamaram completamente e 589 que introduziram a mamadeira no período. A duração do aleitamento total e exclusivo dessas mulheres foi, respectivamente, de 108,5 dias e de 38,5 dias. As "entrevistas múltiplas" foram o resultado de contacto apenas com as 365 mães que compareceram por duas, três ou quatro vezes aos Centros de Saúde.

\section{Razões de introdução da mamadeira}

A Figura 1 nos mostra as razōes mais

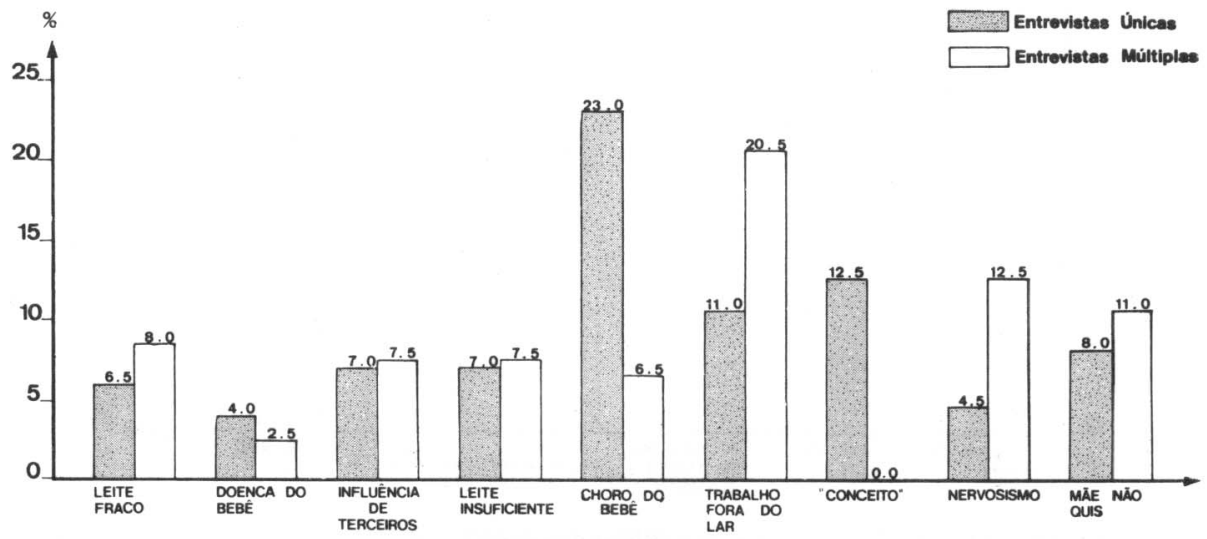

Fig. 1 - Razð̋es de introduçăo da mamadeira mais treqüentes conforme diferentes coletas de dados

Nota - Os denominadores a que se referem estes percentuais são diferentes: na entrevista única, obtivemos pelo registro de mais de uma resposta para cada mãe, 1.032 respostas (referindo-se a ume entrevista, onde cada mãe poderia dar quatro respostas). Nas entrevistas múltiplas computamos respostas de mais de uma entrevista por mãe, o que totalizou 1.212 respostas. 
freqüentes alegadas pela mulheres para introduzir a mamadeira conforme os dois tipos de coleta de dados registrados.

Como se vê, caem as proporçōes de respostas doença do bebê $(4,0 \%$ para $2,5 \%)$, choro $(23,0 \%$

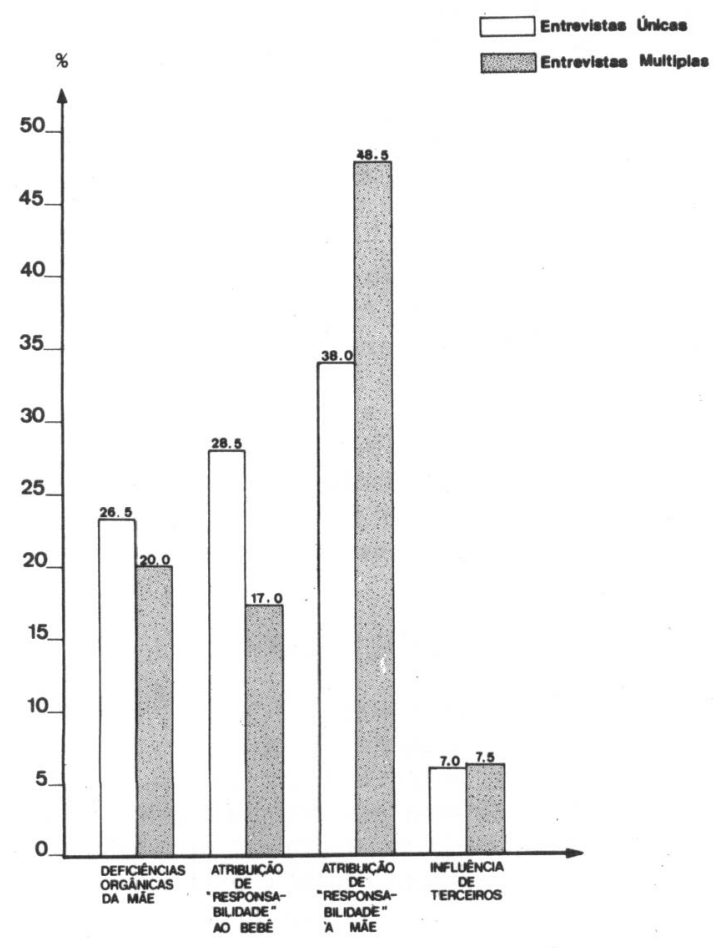

Fig. 2 - Razóes de introduçăo da mamadeira, segundo atribuição de "responsabilidades" conforme diferentes coletas de dados. para 6,5\%), e "conceito"* (de 12,5\% para zero), quando se compara a "entrevista única" com as "entrevistas múltiplas". Em compensação sobem as respostas "tive que trabalhar fora de casa" (de $11,0 \%$ para $20,5 \%$ ) e "nervoso" ou "falta de paciência" (4,5\% para $12,5 \%)$. As demais razðes alegadas permanecem mais ou menos semelhantes nas duas formas de registro de dados, quais sejam: leite fraco ou insuficiente (cerca de 7,0\%), influência de terceiros (cerca de 7,0\%) e o fato de a mảe năo querer amamentar $(8,0 \%$ a $11,0 \%)$.

Quando categorizamos as razões conforme atribuiçăo de "responsabilidade" (Figura 2), notamos que as entrevistas múltiplas permitem-nos agrupar mais respostas que dizem respeito à propria responsabilidade da mulher no processo de desmame (de $38,0 \%$ na análise simples, vai para $48,5 \%$ ), enquanto decrescem tanto a imputação de responsabilidade ao bebê $(28,5 \%$ para $17,0 \%)$ como ao corpo da mãe $(26,5 \%$ para $20,0 \%)$. $A$ influência de terceiros năo se altera.

\section{Razőes de desmame}

Reúnem-se na Figura 3 os achados mais freqüentes de razões alegadas para o desmame completo nas duas formas de análise: entrevistas única e múltiplas.

Notam-se que permanecem relativamente semelhantes e altas nos dois tipos de análise as ražos "bebê năo quis mais mamar" (18,0\% para $17,5 \%)$ e "o leite secou" (17,0\% para $14,5 \%)$ como causas de desmame. As duas formas de análise tampouco diferenciam causas de desmame como relacionadas à saúde da mäe (de $5,0 \%$ para $4,5 \%$ ).

Aumentam, entretanto, as razoes: trabalho da

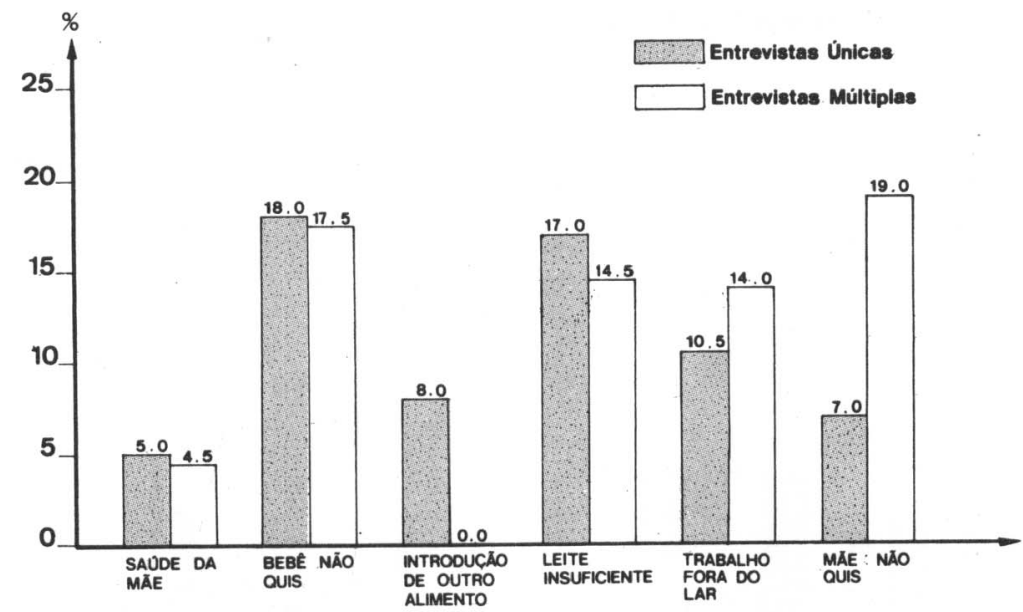

Fig. 3 - Razóes de desmame mais freqüentes conforme diferentes coletas de dados. Nota - Os denominadores săo, para a entrevista única, 752 respostas, e para as entrevistas múltiplas, 772.

- Chama-se aqui de "conceito" ou suposiçôes, razóes de ordem conceitual pré-formadas no pensamento da mãe, do tipo "leite materno tem que ser complementado", "amamentar exclusivamente năo basta", e outros. 


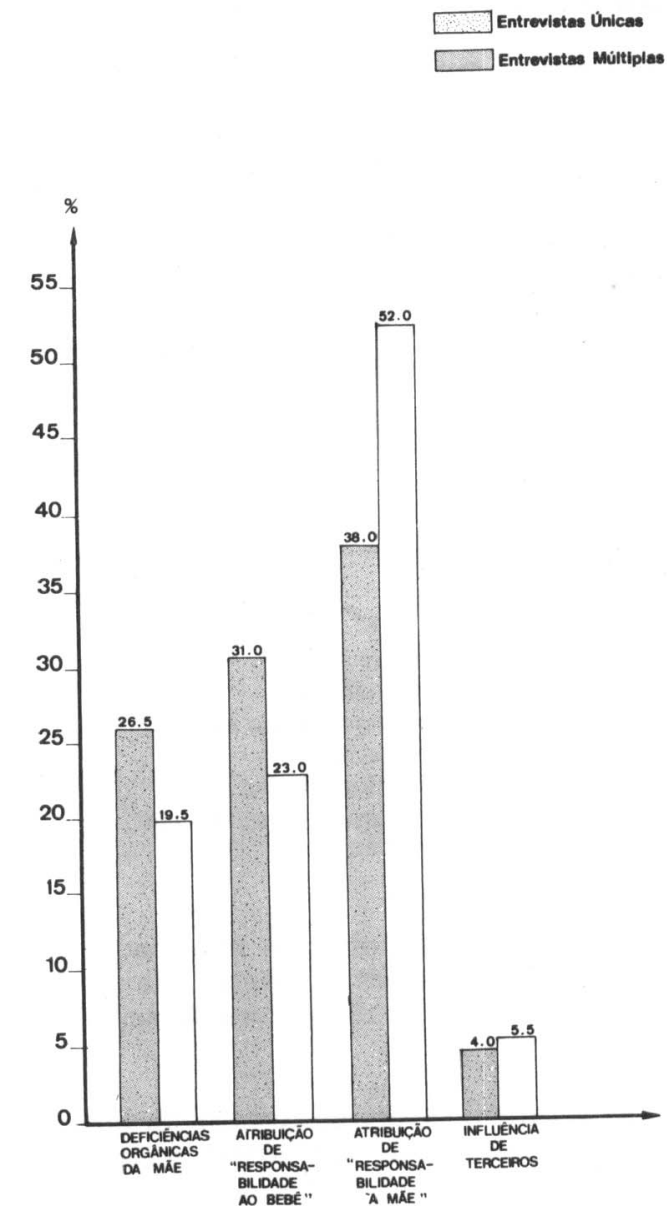

Fig. 4 - Razóes de desmame segundo a atribuiçăo de "responsabilidades", conforme diferentes coletas de dados.

(1)

(2)

(3)

(4) mulher (de $10,5 \%$ para $14,0 \%$ ) e o fato de a mãe interromper a amamentação por não querer mais dar o peito (de $7,0 \%$ para $19,0 \%$ ), sempre quando se comparam a entrevista única com as entrevistas múltiplas. Ainda desta forma, "desaparece" como razăo importante a "introduçăo de outros alimentos, inclusive mamadeira", que na análise simples era mencionada por $8,0 \%$ das mães.

Quando são agrupadas as razóes para fins de análise por atribuição de "responsabilidade" nota-se, como no caso de introdução de mamadeiras, uma queda de $26,5 \%$ para $19,5 \%$ na responsabilidade do corpo da mulher e de $31,0 \%$ para 23,0\% na responsabilizaçăo do bebê, sempre quando se comparam entrevistas únicas com entrevistas múltiplas.

Esta comparação mostra, entretanto, que aumenta a responsabilizaçăo da mãe (de $38,0 \%$ para $50,0 \%$ ) e permanece semelhante e de pequena importância a atribuiçăo de razőes de desmame a terceiros (Figura 4).

\section{DISCUSSÃO}

Os resultados nos mostram que ao darmos à mulher a chance de responder mais de uma causa que a levou seja a desmamar, seja a introduzir a mamadeira, acabamos por recolher um número maior de razóes alegadas e com isto chegamos mais proximo de causas que participam com mais frequeuência no processo de desmame.

Utilizando-se apenas essa metodologia de coleta (e que está sendo chamada de "entrevista única") pudemos traçar o processo de desmame e introduçăo da mamadeira da seguinte forma (hipotética, porém a mais próxima do real neste modo simples de análise):

(5) (6)

fim do período

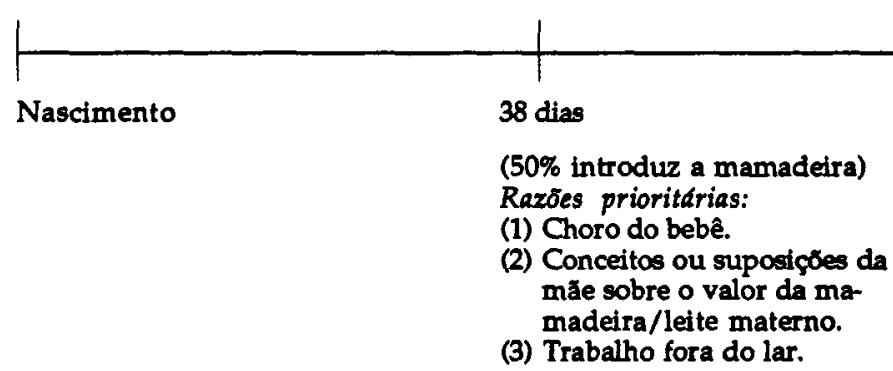
de observaçăo

O desenho acima permite-nos visualizar que para a "mãe - tipo", que participou de nosso estudo, as cinco razð̌es prioritárias mencionadas são aquelas que atuando de forma básica (conceitos sobre o valor da mamadeira/sobre o leite materno; choro do bebê), associada (trabalho fora do lar; bebê năo quis mais mamar) ou final (o "leite secou" ou era insuficiente) constituem as razóes mais importantes do processo de desmame.

Comparando-se o que se obtém com este recurso metodológico com estudos já publicados 9,13 , vê-se que neste se consegue uma concatenaçăo de situaç̧̋es ou circunstâncias que evidenciam um processo de forma mais completa. Não se pode afirmar, entretanto, qual á causa funda- 
mental que levou a mulher a interromper a amamentaçăo. Estranha-se, de qualquer maneira, que conceitos ou suposiçoes da mãe sobre o valor da mamadeira/ou leite materno estejam incluídos nesse encadeamento de nossa "mãetipo", já que a populaçāo em estudo fez parte de um estudo de intervençăo pró-amamentação. Fica sem resposta se as açōes de incentivo năo conseguiram modificar conceitos errôneos da mãe ou se, na medida em que se permitiu a abertura para várias respostas e se criou um bom "rapport" com a equipe, desde a maternidade, a mulher se sentiu a vontade para ser honesta e nåo escamotear suas verdadeiras razōes para introduzir a mamadeira.

Ao darmos à mulher a possibilidade de rever seus discursos e aduzir (ou reformular) razós, vemos que ela verbaliza razóes distanciadas do momento em que o desmame (ou introdução da mamadeira) ocorreu ou mesmo evidencia mais conhecimentos sobre a prática de amamentar pelo contato com nossa equipe. Desta forma, hipoteticamente passa ao desenho gráfico, a seguir, o processo de desmame de nossa "mãetipo".

(1)

(2)

(3)

(4)

(5)
(6)

(7) fim do periodo de observação

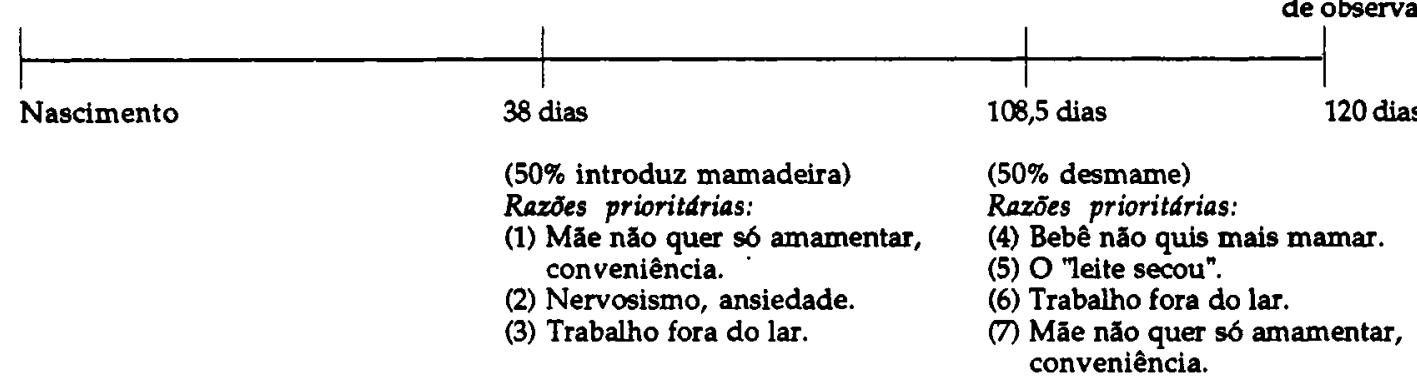

Aparentemente, o avanço que se consegue na identificaçăo do processo de desmame com esta última forma de análise é que a mãe passa a admitir razões de sua responsabilidade e não do bebê na base do processo, quais sejam "nervosismo", "ansiedade" ou "mãe não quer só amamentar". Trabalhar fora do lar assume aqui nesta análise uma importância maior (isto é, mais mães o mencionam como causa prioritária para a entrada da mamadeira ou o desmame) seja como causa associada ou básica. Provavelmente o fato de o bebê não querer mais mamar e o leite se tornar insuficiente são razóes finais do processo, isto é, na hora de desmamar completamente, ao rever o que se passou, a mãe-tipo passa a mencionar honestamente que desmamou porque ela própria não queria amamentar e também porque o "leite secou".

A populaçăo a que esta descrição se refere não pode ser comparada às mảes em geral, pois como mencionamos, esteve sujeita ao apoio de equipes pró-amamentação nos serviços de saúde. Desta forma, este perfil de causas de desmame apontado traz o reforço e continência de "promotoras" da lactação, cuja compreensão do processo implicava sempre permitir à mãe que esta se sentisse mais à vontade. $O$ respeito e a não-coação (ou culpabilidade) à mãe foi constante, dando-lhe chance ora de expor seu desejo, ora de negar sua vantade de amamentar.

Frente às dificuldades que se colocam na vida urbana à mulher pobre, sem apoio social e ao mesmo tempo com necessidades de garantir a sobrevivência; $e$, frente à atitude nem sempre coerente do sistema de saúde quanto à prática de alimentar a criança pequena, parece-nos que é este último o processo de desmame que provavelmente se dá.

Esta elucidação do processo contribui efetivamente para identificarmos razőes sobre as quais o sistema de saúde, através de uma equipe multidisciplinar, deve atuar, e também evidencia que, isoladamente, o sistema de saúde não possui todas as soluçōes para evitar o desmame precoce. É absolutamente necessário que o setor saúde leve em conta o papel da sociedade quanto ao apoio à mulher que amamenta e trabalha fora do lar, quanto a existência de creches no local de trabatho, pausas regulares para amamentar, garantia de emprego aos pais do lactente, licença suficiente, além de outras soluçôes. 
REA, M.F. \& CUKIER, R. [Reasons for weaning and the introduction of bottle-feeding: an alternative approach]. Rev. Saúde públ., S. Paulo, 22: 184 - 91, 1988.

ABSTRACT: Reasons, alleged by mothers, for early weaning and for the introduction of breastmillk substitutes were studied, in 1985, in a public maternity hospital of S. Paulo City. These mothers were part of an intervention project to support and promote breast-feeding through public health services. Eight hundred and seventy-five women were followed up from delivery to the 4th month of the baby's life. Reasons for weaning were collected immediately afterwards ("single interview") and were also again asked for when the mother returned to the health unit ("multiple interview"). All the reasons given were collected and classified according to "responsibility": of the mother (her own desire to wean), of her baby (attributed to the baby), of her body (the mnther's physical reasons) and of other people (doctor, husband, neighbor, etc.). The most prevalent reasons for the introduction of breast-milk substitutes, according to "multiple interview", were: mother had to work out $(20.5 \%)$, got agitated $(12.5 \%)$ and convenience $(11.0 \%)$. According to "single interview" they were: the baby's crying $(23.0 \%)$, prior conceptions of infant feeding $(12.5 \%)$, working out $(11.0 \%)$. These differences were not so evident among the reasons for complete weaning; however, considering weaning as a long process in which the reasons for the introduction of breast-milk substitutes may be linked to reasons for the "sevrage", the advantages of utilizing all the answers of different contacts with the women ("multiple interview") over against just one answer given on one ocasion as a contribution to the clarification of the weaning process in each cultural site, is indicated. The reasons gathered and classified according to "responsibility" show that "multiple interview" beings to light more answers related to the desire to wean on the part of the mother herself than the baby, or the mother's body. It is argued that the health system has limits to its ability to intervene in the most prevalent reasons for early weaning and the necessity for social policies, such as maternity protection legislation, child nurseries, etc., in support of breast-feeding, is commented on.

UNITERMS: Weaning. Bottle-feeding. Mothers. Sociceconomic factors.

\section{REFERÊNCIAS BIBLIOGRÁFICAS}

1. ALMROTH, S. \& LATHAM, M. C. Breast-feeding practices in nural Jamaica. J. trop. Pediat., 28: 103-9, 1982.

2. BROWN, J. \& BROWN, R. Finding the causes of proteincalorie malnutrition in a community. Environ. Child Hlth, 23: 247-61, 1977.

3. CUKIER, R. Duas abordagens para o estudo das razóes de desmame. In: Berquó, E. el al. Caracterizaçāo e determinantes do aleitamento materno na Grande Sáo Paulo e na Grande Recife. São Paulo, CEBRAP, 1984. (Cademos CEBRAP Nova Série 2).

4. DREJER, G. F. Botule-feeding in Donala, Camerrons. J. trop. Pediat., 26: 31-6, 1980.

5. GREINER, T. et al. The insufficient milk syndrome: an altemative explanation. Med . Anthropol., 5: 233-57, 1981.

6. GUSSLER, J. D. \& BRIESEMEISTER, L. H. The insufficient milk syndrome: a biocultural explanation. Med. Anthropol., 4: 1-24, 1980

7. HELSING, E. Feeding practices in Europe: beliefs and motivations and possibilities for change. [Presented at the Intemational Symposium on Infant and Early Childhood Feeding. Michigan State University, 1978].

8. HUFFMAN, S. et al. Breast-feeding pattems in rural Bangladesh. Amer. J. clin. Nur, 33: 144-54, 1980.
9. JANSEN, A. A. J. Malnutrition and child feeding practices among the Gilbertese. Environ. Child Hith, 23: 161-84, 1977.

10. LARKIN, F. A. Pattern of weaning in Dominica. West Indian med. J., 20: 229-36, 1971.

11. LPM Burke. Exploratória sobre aleitamento matemo; relatório. São Paulo, 1981 (LPM 01.81/1363) [Mimeografado].

12. MARCHIONE, T. J. \& HELSING, E., eds. Project report: rethinking infant nutrition policies under chan-ging socioeconomic conditions. Acto paediatr. scand., (Suppl. 314) 1984.

13. MARTINS FILHO, J. et al. Contribuição para o estudo do aleitamento matemo. Pediat. prát.,50: 152-6, 1979.

14. REA, M. F. \& SOLIMANO, G. Rethinking infant nutrition policies under changing socioconomic conditions; São Paulo project. [Presented in Rethinking Infant Nutrition Policies under Changing Socioeconomic Conditions. Oslo, Noruega, 1980].

15. SJÖLN, S. et. al. A prospective study of individual courses of breast-feeding. Acta paediat. scand.,68: 521-9, 1979.

Recebido para publicaçäo em 18/9/1987 Reapresentado em 19/2/1988 Aprovado para publicaçấo em 8/3/1988 